\title{
Casos e Focos de Raiva e Brucelose em Bovinos (Bos taurus) registrados em Roraima no Período 2008-2016
}

\author{
Taiã Mairon Peixoto Ribeiro ${ }^{1}$
}

1. Universidade Federal do Tocantins. (UFT). Campus Araguaína, Curso de Bacharelado em Medicina Veterinária, BR-153, km 112, Zona Rural, CEP 77800-000, Araguaína, TO, Brasil.

Email para correspondência: ribeiro.vet@uft.edu.br

Recebido: 05 de setembro de 2017. Aceito: 21 de novembro de 2017. Publicado PDF : 28 de novembro de 2017.

\section{RESUMO}

Casos e Focos de Raiva e Brucelose em Bovinos (Bos taurus) registrados em Roraima no Período 2008-2016. A brucelose e raiva constituem duas zoonoses que podem acarretar impacto negativo tanto na saúde pública, quando na saúde animal. O estado de Roraima possui um forte potencial de produção agropecuária que pode ter prejuízos principalmente na bovinocultura advindo das infecções pela Brucella abortus e pelo Vírus Rábico. Este estudo analisou a presença de anticorpos anti-Brucella abortus e de anticorpos anti-Vírus Rábico na espécie bovina (Bos taurus) entre os anos de 2008-2016 no estado de Roraima, por meio da consulta de casos e focos em banco de dados do Sistema Nacional de Informação Zoosanitária do Ministério da Agricultura, Pecuária e Abastecimento. O presente estudo teve como objetivo elencar informações epidemiológicas acerca do número de casos e focos em bovinos no estado de Roraima, de modo que se propiciem a adoção e conscientização de medidas preventivas que reduzam o impacto negativo destas zoonoses. Foi observada redução gradual da quantidade de casos e focos de brucelose em bovinos no estado no período analisado passando de 241 casos no ano de 2012 para 8 casos no ano de 2016. Foram registrados 10 casos de raiva bovina, sendo 8 no ano de 2008 e 2 no ano de 2009 . Recomenda-se o reforço nas medidas de defesa sanitária animal, em especial no uso da vacinação de bovinos para brucelose e raiva, bem como no controle de morcegos em regiões em que se constata a presença do vírus rábico em animais e seres humanos.

PALAVRAS CHAVE: Brucella abortus; Saúde Pública; Vírus Rábico.

\section{ABSTRACT}

Cases and focus of Rabies and Brucellosis in Bovines (Bos taurus) registered in Roraima in the period 20082016. Brucellosis and rabies are two zoonoses that can have a negative impact on both public health and animal health. The state of Roraima has a strong potential of agricultural production that can have losses mainly in the livestock coming from the infections by Brucella abortus and by Rabies Virus. This study analyzed the presence of anti -Brucella abortus antibodies and anti-Rabies Virus antibodies in the bovine species (Bos taurus) between the years 2008-2016 in the state of Roraima, through the consultation of cases and focus in the System database National Zoosanitary Information of the Ministry of Agriculture, Livestock and Supply. The present study aimed at listing epidemiological information on the number of cases and outbreaks in cattle in the state of Roraima, in order to promote the adoption and awareness of preventive measures that reduce the negative impact of these zoonoses. It was observed a gradual reduction in the number of cases and outbreaks of brucellosis in cattle in the state in the analyzed period, from 241 cases in 2012 to 8 cases in 2016 . There were 10 cases of bovine rabies, 8 in 2008 and 2 in 2009 . It is recommended to reinforce animal health protection measures, especially in the use of bovine vaccination for brucellosis and rabies, as well as in bat control in regions where exists the presence of rabies virus in animals and humans.

KEY WORDS: Brucella abortus; Public health; Rabies Virus. 


\section{INTRODUÇÃO}

A brucelose em bovinos é causada pela bactéria Brucella abortus, sendo considerada endêmica no Brasil, no entanto devido as diferenças regionais podem ocorrer diferenças em relação a prevalência da doença em cada unidade da federação (Zapata et al. 1998; Brasil 2006; Mello et al. 2007; Sola et al. 2014). Bezerra (2011) verificou 8,0\% de prevalência de anticorpos anti-Brucella abortus em um total de 74.130 amostras de sangue de bovinos coletadas em Roraima no período de 20052010. Souza et al. (2012) por sua vez, constataram 106 focos de brucelose bovina em Roraima e prevalência de $4,1 \%$ de anticorpos anti-Brucella abortus em um total de 9.456 amostras sanguíneas de bovinos entre os anos de 2007 a 2009. O Ministério da Agricultura, Pecuária e Abastecimento (MAPA) determina que devem ser utilizados no diagnóstico da brucelose bovina os testes do antígeno acidificado tamponado, teste do 2mercaptoetanol associado ao de soroaglutinação lenta, teste de polarização fluorescente e teste do anel em leite (Brasil 2017a).

A raiva bovina é uma zoonose provocada por um vírus RNA que possui tropismo pelo tecido nervoso, da família Rhabdoviridae, gênero Lyssavirus, causando encefalite aguda em diversas espécies de mamíferos, sendo a espécie bovina a mais acometida pela doença (Wada et al. 2011; Braga et al. 2013). A raiva bovina está ligada a presença de morcegos hematófagos nas zonas rurais, onde os quirópteros possuem abrigos naturais ou artificiais (Kotait et al. 2007; Genaro 2010; Souza et al. 2014; Reis et al. 2003). Como os sinais da raiva bovina são inespecíficos, o MAPA preconiza o uso do Teste de Imunofluorescência Direta (TIFD) e Prova Biológica em camundongos (PB) para o diagnóstico da raiva em bovinos (Brasil 2012). Outros testes também auxiliam no diagnóstico e podem ser utilizados como a histopatologia do sistema nervoso central na observação dos corpúsculos de Negri, bem como a reação em cadeia de polimerase convencional e quantitativa (Souza 2011; Oliveira et al. 2012).

$\mathrm{O}$ presente trabalho objetivou avaliar os casos e focos verificados pela presença de infecção por Brucella abortus e Vírus Rábico em bovinos baseados em testes sorológicos preconizados pelo MAPA no estado de
Roraima, por meio de consulta ao Sistema Nacional de Informação Zoosanitária (SIZMAPA) entre os anos de 2008 e 2016.

\section{MATERIAL E MÉTODOS}

O estado de Roraima se encontra localizado entre as latitudes $1^{\circ} 35^{\prime} 11^{\prime \prime} \mathrm{S}$ e $5^{\circ}$ $16^{\prime} 20^{\prime \prime} \mathrm{N}$, longitude $-60^{\circ} \mathrm{W}$ e $-65^{\circ} \mathrm{W}$, e possui clima equatorial (Rodrigues 2015). Possui rebanho de 794.783 bovinos de acordo com dados do Instituto Brasileiro de Geografia e Estatística acerca da produção pecuária municipal de 2015 (Brasil 2015).

O estudo é retrospectivo e descritivo da quantidade de casos e focos confirmados de raiva e brucelose em bovinos no estado entre os anos de 2008-2016. Definiu-se como caso, o animal doente ou infectado com diagnóstico confirmado e foco como a unidade epidemiológica em que foi verificado ao menos um caso de bovino positivo ao teste. Foram avaliadas informações constantes na base de dados do SIZ-MAPA relativos ao estado de Roraima no período de 2008-2016 (Brasil 2017b).

\section{RESULTADOS E DISCUSSÃO}

No período entre 2008-2016 foram notificados 153 focos e 714 casos confirmados de brucelose em bovinos neste período (Quadro 1).

Constatou-se que o número de focos e casos vem decrescendo em Roraima, no entanto a falta de outros dados não permite sugerir se tal redução é decorrente de possível deficiência na vigilância epidemiológica pela Agência Estadual de Defesa Agropecuária do estado de Roraima (ADERR), maior adesão dos produtores as ações preconizadas pelo Programa Nacional de Controle e Erradicação da Brucelose e da Tuberculose Animal (PNCEBT) ou ainda ao aumento das ações em defesa sanitária animal pela ADERR.

$\mathrm{O}$ registro de casos e focos constatados no presente estudo difere daquele encontrado por Souza et al. (2012) que verificaram 369 casos de bovinos positivos e 106 focos no período de 2007-2009, fato este que evidencia a necessidade de inserção de mais dados no SIZMAPA, especialmente do número de casos e focos anteriores ao período 2008-2016. 
Quadro 1- Número de focos e casos de brucelose bovina no estado de Roraima no período de 2008-2016.

\begin{tabular}{|c|c|c|}
\hline Ano & $\begin{array}{c}\text { Número de } \\
\text { Focos }\end{array}$ & $\begin{array}{c}\text { Número de } \\
\text { Casos }\end{array}$ \\
\hline 2008 & - & - \\
\hline 2009 & - & - \\
\hline 2010 & - & - \\
\hline 2011 & - & - \\
\hline 2012 & 48 & 241 \\
\hline 2013 & 41 & 233 \\
\hline 2014 & 33 & 156 \\
\hline 2015 & 24 & 76 \\
\hline 2016 & 7 & 8 \\
\hline Total & $\mathbf{1 5 3}$ & $\mathbf{7 1 4}$ \\
\hline
\end{tabular}

Observa-se que o número de casos observados no presente estudo é maior no estudo de Souza et al. (2012), no entanto o número de focos é menor do que aquele constatado na base de dados do SIZ-MAPA.

Bezerra (2011) em outro estudo realizado no estado de Roraima verificou total de 5.774 amostras positivas de bovinos no período de 2005 a 2010. Tais dados, embora divirjam em relação a quantidade de casos em períodos sobrepostos ou não, tais estudos evidenciam a presença da infecção pela bactéria em bovinos (mas não necessariamente a doença) verificado por métodos sorológicos de diagnóstico, o que constitui fator de risco para infecção para outros bovinos, para os seres humanos que poderão se infectar pela ingestão de produtos lácteos ou carne mal cozida ou pelo contato direto, a exemplo de trabalhadores rurais que mantém contato direto com os animais (Zapata et al. 1998).

Souza et al. (2012) constataram como fatores de risco por meio da regressão logística para o contato com a infecção por B. abortus em bovinos no estado de Roraima a presença de mais de 51 cabeças na propriedade e o aluguel de pastos, o que sugere que propriedades com um número acima de 51 cabeças eleva a proporção de bovinos expostos a infecção por $B$. abortus, além disso o aluguel de pastos propicia o contato de bovinos com outras propriedades havendo contaminação da água e pasto oferecidos aos animais (Souza et al. 2012). Portanto, ressalta-se que se deve requisitar antes da entrada do animal na propriedade o comprovante de que o animal foi submetido ao diagnóstico oficial para infecção por B. abortus em laboratório credenciado, além da aplicação da quarentena, vacinação com a cepa B19 em fêmeas de três a oito meses de idade, descarte de fêmeas soropositivas e evitar o aluguel de pastos para outras propriedades (Brasil 2006; Jardim et al. 2006; Souza et al. 2012; Sola et al. 2014).

Em relação a infecção pelo vírus rábico em bovinos foram notificados apenas dois focos no período avaliado (2008-2016) e 10 casos, sendo oito casos no ano de 2008 e dois no ano de 2009 (Quadro 2).

Quadro 2- Número de casos e de focos de raiva bovina no estado de Roraima no período de 2008-2016.

\begin{tabular}{|c|c|c|}
\hline Ano & $\begin{array}{c}\text { Número de } \\
\text { Focos }\end{array}$ & $\begin{array}{c}\text { Número de } \\
\text { Casos }\end{array}$ \\
\hline 2008 & 1 & 8 \\
\hline 2009 & 1 & 2 \\
\hline 2010 & - & - \\
\hline 2011 & - & - \\
\hline 2012 & - & - \\
\hline 2013 & - & - \\
\hline 2014 & - & - \\
\hline 2015 & - & - \\
\hline 2016 & - & - \\
\hline Total & $\mathbf{2}$ & $\mathbf{1 0}$ \\
\hline
\end{tabular}

A raiva em bovinos é endêmica no Brasil diferindo apenas pelas características ambientais de cada região de acordo com a receptividade da região para reprodução de morcegos hematófagos, tais como presença de abrigos naturais ou não (Souza 2011).

A Coordenação da raiva dos herbívoros e das encefalopatias espongiformes transmissíveis do MAPA (CRHEET-MAPA) realizou avaliação dos indicadores epidemiológicas da raiva em todos os estados do Brasil no período de 2006-2012 e verificou nos estados de Roraima, Acre, Amazonas e Amapá a existência de um sistema de 
notificação e investigação deficiente de doenças neurológicas em herbívoros com base na reduzida vigilância no rebanho bovino, possibilitando a presença de áreas silenciosas para o vírus rábico, além da possibilidade da presença da circulação em animais silvestres na região amazônica e elevada oferta de abrigos em ocos de árvores (Kotait et al. 2007; Brasil 2013a). No mesmo documento os técnicos do MAPA já relatavam o risco da ocorrência da raiva na população humana e Souza (2011) também relatou o ataque a seres humanos por morcegos hematófagos em município limítrofe a Boa Vista, onde no ano de 2016 foi verificado um caso humano de raiva por meio da mordida de felino infectado com vírus rábico proveniente de uma variante 3 de morcego hematófago (Albas et al. 2009; Brasil 2013a; Moura 2016).

Schneider \& Santos-Burgoa (1995) destacam que podem ter havido a existência de casos de raiva em mineradores de ouro que foram atacados por morcegos em Roraima, no entanto a doença não foi confirmada. Souza (2011) realizou a captura de espécimes de Desmodus rotundus em cinco municípios populosos de Roraima, inclusive na capital (Boa Vista, Amajari, Alto Alegre, Rorainópolis e Caracaraí). Portanto, os dados encontrados no presente estudo (10 casos de bovinos positivos para o vírus rábico na base de dados do SIZMAPA), a presença do morcego hematófago no espaço urbano constatado por Souza (2011) e a ocorrência de um caso humano de raiva no município de Boa Vista relatado por Moura (2016) comprovam, respectivamente, a existência da presença de anticorpos anti-Vírus rábico (sugestivo da circulação viral), da presença do reservatório e transmissor do vírus da raiva, e da infecção humana pelo vírus rábico no espaço urbano.

Os bovinos infectados pelo vírus rábico também podem albergar o patógeno podendo ter um período de incubação de 60 a 75 dias em condição de campo (Brasil 2009). No caso de outro morcego não infectado que venha a se alimentar do bovino infectado, então o morcego hematófago poderá se infectar e infectar outros morcegos e outras espécies de produção tais como os equinos, caprinos, ovinos e suínos, além de poder infectar ainda animais silvestres e seres humanos. Para o controle desta zoonose em bovinos recomenda-se a vacinação nos locais de risco, tais como propriedades próximas a abrigos de morcegos e regiões que apresentaram casos recentes de raiva, bem como no controle populacional de morcegos (Brasil 2009).

As duas zoonoses (Brucelose e raiva) são de notificação compulsória ao Ministério da Saúde, no caso da doença na espécie humana, e ao Ministério da Agricultura, Pecuária e Abastecimento, no caso da doença ou infecção em animais (Brasil 2013b; Brasil 2016). A abordagem One health pode ser utilizada no controle destas zoonoses, pois o enfrentamento a estas doenças requer uma gestão eficiente e interdisciplinar (Häsler et al. 2014).

\section{CONSIDERAÇÕES FINAIS}

Observou-se no período analisado que foi realizada a notificação de um número reduzido de casos e focos para vírus rábico e $B$. abortus baseados em testes sorológicos o que constitui perigo a saúde pública.

Para controlar as doenças provocadas por estes patógenos recomenda-se a vacinação de bovinos, proteção dos trabalhadores rurais com o uso de equipamentos de proteção individual, vigilância epidemiológica e intensificação das ações em defesa sanitária animal. .

\section{REFERÊNCIAS BIBLIOGRÁFICAS}

Albas, A.; Souza, E.A.N.; Lourenço, R.A.; Favoretto, S.R. \& Sodré, M.M. 2009. Perfil antigênico do vírus da raiva isolado de diferentes espécies de morcegos não hematófagos da Região de Presidente Prudente, Estado de São Paulo. Revista da Sociedade Brasileira de Medicina Tropical 42(1): 15-17.

Brasil. Ministério da Agricultura, Pecuária e Abastecimento. 2006. Manual técnico do programa nacional de controle e erradicação da brucelose e da tuberculose bovina. Ministério da Agricultura, Pecuária e Abastecimento, Brasília, 184p.

Brasil. Ministério da Agricultura, Pecuária e Abastecimento. 2009. Controle da raiva dos herbívoros: manual técnico 2009. Ministério da Agricultura, Pecuária e Abastecimento, Brasília, $124 \mathrm{p}$.

Brasil. Ministério da Agricultura, Pecuária e Abastecimento. Secretaria de Defesa Agropecuária. 2012. Instrução Normativa $\mathrm{N}^{\circ} 8$, de 12 de abril de 2012. Define os requisitos e critérios para a realização do diagnóstico de raiva, por meio dos métodos denominados Teste de Imunofluorescência Direta (TIFD) e Prova Biológica em camundongos 
(PB). Brasília: Ministério da Agricultura, Pecuária e Abastecimento. 2012. 7 p.

Brasil. Ministério da Agricultura, Pecuária e Abastecimento. Secretaria de Defesa Agropecuária. Coordenação Geral de Combate a Doenças Coordenação da raiva dos herbívoros e das encefalopatias espongiformes transmissíveis. 2013a. Análise de indicadores epidemiológicos da raiva dos herbívoros no Brasil (periodo 2006/2012. Ministério da Agricultura, Pecuária e Abastecimento, Brasília, $37 \mathrm{p}$.

Brasil. Ministério da Agricultura, Pecuária e Abastecimento. Secretaria de Defesa Agropecuária. 2013b. Instrução Normativa $\mathrm{N}^{\circ} 50$, de 23 de setembro de 2013. Alterar a lista de doenças passíveis da aplicação de medidas de defesa sanitária animal. Diário Oficial da União. Seção 1.

Brasil. Ministério da Saúde. 2016. Guia de Vigilância em Saúde. 1 st ed. Ministério da Saúde, Brasília, 773p.

Brasil. Instituto Brasileiro de Geografia e Estatística. Brasil. Instituto Brasileiro de Geografia e Estatística (IBGE). Ministério do Planejamento, Orçamento e Gestão. 2015. Pecuária - 2015 bovino - efetivo dos rebanhos comparação entre os municípios: Roraima. Instituto Brasileiro de Geografia e Estatística, Rio de Janeiro. (http:// cod.ibge.gov.br/1KG6K). Acesso em 04/05/2017.

Brasil. Ministério da Agricultura, Pecuária e Abastecimento. Secretaria de Defesa Agropecuária. 2017a. Instrução Normativa SDA No 10, de 3 de março de 2017. Fica estabelecido o Regulamento Técnico do Programa Nacional de Controle e Erradicação da Brucelose e da Tuberculose Animal - PNCEBT e a Classificação das Unidades da Federação de acordo com o grau de risco para as doenças brucelose e tuberculose, assim como a definição de procedimentos de defesa sanitária animal a serem adotados de acordo com a classificação. Diário Oficial da União. Seção 1, $\mathrm{N}^{\circ}$ 116.

Brasil. Ministério da Agricultura, Pecuária e Abastecimento. 2017b. Sistema Nacional de Informação Zoonosanitária - Coordenação de Informação e Epidemiologia - Saúde Animal. Ministério da Agricultura, Pecuária e Abastecimento, Brasília. (http://indicadores.agricultura.gov.br/ saudeanimal/index.htm). Acesso em 04/05/2017.

Bezerra, D.F.M. 2011. Situação epidemiológica de brucelose bovina no estado de Roraima. Monografia de Conclusão de Curso de Bacharelado em Zootecnia, Universidade Federal de Roraima, Boa Vista. 61p.

Braga, J.F.V.; Souza F.A.L.; Franklin F.L.A.A.; Beserra, E.E.A.; Barreto F.M.; Araújo Neto, J.C.; Costa, F.A.L. \& Silva, S.M.M.S. 2013. Surto de raiva em bovinos no estado do Piauí, Brasil. Acta Veterinaria Brasilica 7(2): 176-179.

Genaro, G. 2010. Gato doméstico: futuro desafio para controle da raiva em áreas urbanas? Pesquisa Veterinária Brasileira 30(2): 186-189.

Häsler, B.; Hiby, E.; Gilbert, W.; Obeyesekere, N.; Bennani, H. \& Rushton, J. 2014. A One Health Framework for the Evaluation of Rabies Control Programmes: A Case Study from Colombo City, Sri Lanka. PloS Neglected Tropical Diseases 8(10): e3270.

Jardim, G.C.; Pirs, P.P.; Mathias, L.A.; Ribeiro, O.C. \& Kuchembuck, M.R.G. 2006. Diagnóstico sorológico da brucelose bovina em animais adultos vacinados com dose reduzida da cepa 19 de Brucella abortus. Pesquisa Veterinária Brasileira 26(3): 177-182.

Kotait, I.; Carrieri, M.L.; Carnieli Junior P.; Castilho, J.G.; Oliveira, R.N.; Macedo, C.I.; Ferreira, K.C.S. \& Achkar, S.M. 2007. Reservatórios silvestres do vírus da raiva: um desafio para a saúde pública. Boletim Epidemiológico Paulista 4(40): 2-8.

Mello, C.C.F.; Souza, D.U.; Glória, F.A.C.; Moura, L.O. \& Mello, G.C.F. 2007. Espondilodiscite por brucelose: relato de caso. Revista da Sociedade Brasileria de Medicina Tropical 40(4): 469-472.

Moura, M.V.M. 2016. Raiva Humana: relato de caso e revisão de literatura. Monografia de Conclusão de Curso de Bacharelado em Medicina, Universidade Federal de Roraima, Boa Vista. 67p.

Oliveira, T.S.; Bull, V.; Rezende, C.A.; Furtini, R.; Costa, E.A.; Paixão, T.A. \& Santos, R.L. 2012. Perfil das amostras do sistema nervoso central de bovinos com síndrome neurológica e diagnóstico da raiva bovina no serviço de defesa sanitária de Minas Gerais, 2003-2010. Pesquisa Veterinária Brasileira 32(4): 333-339.

Reis, M.C.; Costa, J.N.; Peixoto, A.P.C.; Figueiredo, L.J.C.; Menezes, R.V., Ferreira, M.M. \& Sá, J.E.U. 2003. Aspectos clínicos e epidemiológicos da raiva bovina apresentados na casuística da Clínica de Bovinos (Oliveira dos Campinhos, Santo Amaro, Bahia), Universidade Federal da Bahia, durante o período de janeiro de 1990 a dezembro de 1999 (Relato de caso). Revista Brasileira de Saúde e Produção Animal 4(1): 12-17.

Rodrigues, H.A.N.R. 2015. Doenças negligenciadas no estado de Roraima: uma análise a partir da geografia da saúde para o período de 2000-2013. Dissertação de Mestrado, Centro Universitário Univates/RS, Lajeado. 158p.

Schneider, M.C. \& Santos-Burgoa, C. 1995. Algunas consideraciones sobre la rabia humana transmitida por murciélago. Salud Pública de México 37(4): 354 $-362$.

Sola, M.C.; Freitas, F.A.; Sena, E.L.S.; Mesquita, A.J. 
2014. Brucelose bovina: revisão. Enciclopédia Biosfera 10(18): 686-714.

Souza, J.R. 2011. Pesquisa do Virus da Raiva em Quirópteros no estado de Roraima pelo Método de $R T$-PCR. Dissertação de Mestrado, Universidade Federal de Roraima, Boa Vista. 53p.

Souza, L.P.A.; Brasil, A.W.L.; Parentoni, R.N.; Azevedo, E.O.; Alves, C.J. \& Azevedo, S.S. 2012. Brucelose bovina no estado de Roraima: estudo retrospectivo. Arquivos do Instituto Biológico 79(3): 319-325.

Souza, P.G.; Amaral, B.M.P.M.; Gitti, C.B. 2014. Raiva animal na cidade do Rio de Janeiro: emergência da doença em morcegos e novos desafios para o controle. Revista do Instituto Adolfo Lutz 73(1): 119124.

Wada, M.Y.; Rocha, S.M. \& Maia-Elkhoury, A.N.S. 2011. Situação da Raiva no Brasil, 2000 a 2009. Epidemiologia e Serviços de Saúde 20 (4): 509-518.

Zapata, M.R.; Santos, J.S.; Martínez, L.S. \& Soto, M.A. 1998. Brucelosis. Aspectos patogénicos. Clínica, diagnóstico y tratamiento. Formas específicas de enfermedad. Medicine 7(79): 3651-3658. 